Journal of Mathematics and Statistics 8 (3): 396-402, 2012

ISSN 1549-3644

(C) 2012 Science Publications

\title{
Spatial Durbin Model to Identify Influential Factors of Diarrhea
}

\author{
${ }^{1}$ Rokhana Dwi Bekti and ${ }^{2}$ Sutikno \\ ${ }^{1}$ Department of Statistics and Computer Science, \\ School of Computer Science, Bina Nusantara University, \\ J1. K.H Syahdan no. 9, Palmerah, Jakarta Barat, 11480, Indonesia \\ ${ }^{2}$ Departmen of Statistics, Faculty of Mathematics and Natural Sciences, \\ Institut Teknologi Sepuluh Nopember Surabaya, \\ Kampus ITS Sukolilo, Surabaya, 60111, Indonesia
}

\begin{abstract}
Problem statement: An analysis of regression modeling which influenced by the characteristics of the region is very important. That modeling is the spatial autoregressive model. One type of spatial autoregressive model is a Spatial Durbin Model (SDM), which performs a lag effect of the dependent and independent variables. This model was developed because the dependencies in the spatial relationships doesn't only occur in the dependent variable, but also on the independent variables. Modeling of diarrhea and the factors that influence is the case that followed this method. Approach: This problem was solved by identification of spatial autocorrelation and modeling to get the influence factors of diarrhea. The modelings were Ordinary Least Square (OLS) and SDM. Then, it was compared between two models. This research located in Tuban Regency, East Java, Indonesia. Results: There were a spatial autocorrelation on diarrhea and the factors variable that influence it. Furthermore, the SDM was giving better performance than OLS model. The results of SDM showed that the lag in the dependent and independent variables significantly affected. These independent variables were source of drinking water, health center and medical personnel which were significant at $\alpha=5 \%$. Conclusion: SDM has good performance to identify influential factors of diarrhea which has spatial factors.
\end{abstract}

Key words: Diarrhea, spatial, spatial durbin model

\section{INTRODUCTION}

Spatial method is a method to get information of observations influenced by space or location effect. Spatial model often use dependency relationship in the form of covariance structure through autoregressive model (Wall, 2004). LeSage and Pace (2009) stated that the autoregressive process is indicated by the dependency relationship among a set of observations or locations.

Anselin (1988) has shown that one model of spatial autoregressive is Mixed Regressive-Autoregressive, which the function is $y=\rho \mathrm{W}_{1} \mathrm{y}+\mathrm{X} \beta_{1}+\varepsilon$. It shows the spatial lag effect on the dependent variable. Spatial relationship among observations is expressed by the weight matrix $\left(\mathrm{W}_{1}\right)$. Parameter $\rho$ is the spatial lag parameter on dependent variable and $\beta_{1}$ is spatial lag parameter on the independent variable. The model called a Mixed Regressive-Autoregressive model because it combines the linear regression and a spatial lag regression model on the dependent variable. The model is also called the Spatial Autoregressive Models (SAR).

Special cases of SAR mode is add lag effect of the independent variables, so that the model is $\mathrm{y}=\rho \mathrm{W}_{1} \mathrm{y}+$ $\beta_{0}+X \beta_{1}+W_{1} X \beta_{2}+\varepsilon$. $\beta_{2}$ is parameter of lag on $W_{1} X$. This model is called Spatial Durbin Model (SDM). This model was developed because the dependencies in the spatial relationships not only occur in the dependent variable, but also on the independent variables. Therefore, it is necessary to add spatial lag $\mathrm{W}_{1} \mathrm{X}$.

The researchers who discuss about SDM are Kissling and Carl (2007). This research was about biological and autocorrelation spatial is affected on dependent and independent variables. Also, Brasington and Hite (2005) were modeled characteristic and location of houses and the price of houses. The results were neighboring or dependencies on independent variable are significant.

Corresponding Author: Rokhana Dwi Bekti, Department of Statistics and Computer Science, School of Computer Science, Bina Nusantara University, Jl. K.H Syahdan no. 9, Palmerah, Jakarta Barat, 11480, Indonesia 
Spatial modeling has also been developed in the healthy and environment cases, such as Myaux et al. (1997) and Kazembe et al. (2009). Myaux et al. (1997) showed that the analysis of health data which included related to space is very important in epidemiological research and healthy planning of infectious diseases. This research aims to looking at the geographic distribution of acute watery diarrhea cases in community and to assess the disease which is more common in certain areas. Murad (2011) used GIS in health care planning in Jeddah City. This application was considered as spatial decision suport system for health planners. In other various fields are agriculture, meteorology, forestry, poverty and econometrics. Elobaid et al. (2009) investigated the spatial correlation of the mean diameter of trees. In poverty, Bekti and Sutikno (2011) use Geographically Weighted Regression (GWR) to modeling on the relationship between asset society and poverty in East Java, Indonesia.

A diarrhea case in public was influenced by physical and environmental conditions, socioeconomic and cultural as well as where they live. The indicators used are the criteria of availability of sanitation and wastewater infrastructure and the criteria for resident status. These indicators can be used to determine the factors that influence diarrhea.

In Tuban Regency, Indonesia, diarrhea was one of the health problems until now. According to data from the Health Department 2007, diarrhea was occupies the second highest percentage after acute respiratory infections by $18.05 \%$. Susenas data 2007 shows that the percentage of patients with diarrhea was $0.73 \%$. Arumsari and Sutikno (2010) have analyzed the incidence of diarrhea in Tuban with spatial models. The variables that significanly affect are the availability of drinking water facilities and distance of the home with feces landfills (less than $10 \mathrm{~m}$ ). The spatial modeling used was Geographically Weighted Poisson Regression (GWPR) which is the approach point. It was need the development of spatial modeling which approach to spatial area and use the spatial effect on dependent and independent variables. So, this research is modelling SDM to identify factors that affect the incidence of diarrhea in Tuban Regency.

\section{MATERIALS AND METHODS}

The data used in this study are the data from Susenas, Central Bureau of Statistics Indonesia in 2007, Tuban Regency Figures 2008 and Department of Health. The research locations are 20 districts in Tuban. Variables used in the study include the dependent and independent variables in Table 1 . The analysis steps are:

- Exploration data to determine the pattern of dependency on each variable

- Test of spatial dependence or autocorrelation with Moran's I for each variable. Type of weighted matrix which used was rook continguity

- Ordinary Least Square (OLS) modeling (parameter estimation, hypothesis test and residual assumptions)

- Spatial Durbin Model (parameter estimation, hypothesis test)

- Compared SDM and OLS models

Moran's I: Moran's I coefficient is used to test the spatial dependence or autocorrelation between observations or location (Lee and Wong, 2001).

Table 1: Variables

\begin{tabular}{|c|c|c|}
\hline Code & Variable & Definition \\
\hline \multicolumn{3}{|l|}{ Dependent variable } \\
\hline $\mathrm{Y}$ & Diarrhea & $\begin{array}{l}\text { Percentage of population with diarrheal disease and } \\
\text { registered in health centers in every district. }\end{array}$ \\
\hline Independent variables $(\mathbf{X})$ : & & Ownership of sanitation facilities, clean water and health facilities. \\
\hline $\mathrm{X}_{1}$ & Source of drinking water & $\begin{array}{l}\text { Percentage of households who uses drinking water from rainwater, } \\
\text { rivers, unprotected springs and unprotected wells }\end{array}$ \\
\hline $\mathrm{X}_{2}$ & $\begin{array}{l}\text { The distance of pumps/ wells } \\
\text { /springs to shelter dirt/feces }\end{array}$ & $\begin{array}{l}\text { Percentage of households who have pumps, wells, } \\
\text { or springs into shelters dirt or feces less than } 10 \mathrm{~m}\end{array}$ \\
\hline $\mathrm{X}_{3}$ & Water facilities & Percentage of households who don't have water facilities \\
\hline $\mathrm{X}_{4}$ & Defecate facilities & $\begin{array}{l}\text { Percentage of households who don't have defecated facilities } \\
\text { (latrine/toilet). }\end{array}$ \\
\hline $\mathrm{X}_{5}$ & Type of toilet & $\begin{array}{l}\text { Percentage of households who have type of toilet } \\
\text { cubluk/cemplung or don't have toilet. }\end{array}$ \\
\hline $\mathrm{X}_{6}$ & Landfills feces & $\begin{array}{l}\text { Percentage of households who have a bowel movement in the } \\
\text { pond/rice field, river/lake/sea, ground holes and beach/terrain }\end{array}$ \\
\hline $\mathrm{X}_{7}$ & Health Center & Ratio of number of health center and populations \\
\hline $\mathrm{X}_{8}$ & Medical Personnel & Ratio of number of medical personnel and populations \\
\hline
\end{tabular}


The formula of hypothesis test is Eq. 1:

$$
\mathrm{Z}=\frac{\mathrm{I}-\mathrm{I}_{\mathrm{o}}}{\sqrt{\operatorname{var}(\mathrm{I})}}
$$

Where:

$$
\begin{gathered}
I=\frac{n}{\sum_{i=1}^{n} \sum_{j=1}^{n} w_{i j}} \frac{\sum_{i=1}^{n} \sum_{j=1}^{n} w_{i j}\left(x_{i}-\bar{x}\right)\left(x_{j}-\bar{x}\right)}{\sum_{i=1}^{n}\left(x_{j}-\bar{x}\right)^{2}} \\
E(I)=I_{o}=-\frac{1}{n-1}
\end{gathered}
$$

Var (I) is the variance of Moran's I and E (I) is the expected value. Reject Ho and there is a spatial autocorrelation if $|Z|>Z_{\alpha / 2}$. The value of Moran's I is between -1 and 1 . Value $I>I_{0}$ is shows the positive autocorrelation and $\mathrm{I}<\mathrm{I}_{0}$ is shows the neagtive autocorrelation.

Spatial durbin model: General model of Spatial Autoregressive (SAR) is shown in Eq. 2 and 3 (LeSage, 1999; Anselin, 1988):

$y=\rho W_{1} y+X \beta+u$

And:

$\mathrm{u}=\lambda \mathrm{W}_{2} \mathrm{u}+\varepsilon$

$\varepsilon \sim \mathrm{N}\left(0, \sigma^{2} \mathrm{I}\right)$

where, y represent vector of dependent variable $(n \times 1)$, $\mathrm{X}$ represent matrix of independent variable $(\mathrm{n} \times(\mathrm{k}+1))$, $\beta$ represent vector of regression coefficient parameter $((\mathrm{k}+1) \times 1), \rho$ represent spatial lag coefficient parameter on dependent variable, $\lambda$ represent spatial lag coefficient parameter on error $\mathrm{u}$ and $\varepsilon$ error $(\mathrm{n} \times 1), \mathrm{W}_{1}$ and $\mathrm{W}_{2}$ represent weighted matrix $(\mathrm{n} \times \mathrm{n})$, I represent identity matrix $(n \times n), n$ represent number of observations or locations $(i=1,2,3, \ldots, n)$ and $\mathrm{k}$ represent number of independent variable $(\mathrm{k}=1,2,3, \ldots, 1)$.

If $\mathrm{X}=0$ and $\mathrm{W}_{2}=0$, Equation 2 would be first order spatial autoregressive model $y=\rho \mathrm{W}_{1} \mathrm{y}+\varepsilon$. This model represents the variance on $y$ as linear combination of variance among neighboring locations without independent variable. If $\mathrm{W}_{2}=0$ or $\lambda=0$, Equation 2 would be Mixed Regressive-Autoregressive model or Spatial Autoregressive Model (SAR) y = $\rho \mathrm{W}_{1} \mathrm{y}+\mathrm{X} \beta+\varepsilon$. This model assumed that autoregressive process just on dependent variable.
If $\mathrm{W}_{1}=0$ or $\rho=0$, Eq. 2 would be Spatial Error Model (SEM) y $=\mathrm{X} \beta+\lambda \mathrm{W}_{2} \mathrm{u}+\varepsilon . \lambda \mathrm{W}_{2} \mathrm{u}$ is represents structure spatial $\lambda \mathrm{W}_{2}$ on spatially dependent error $(\varepsilon)$. When $\mathrm{W}_{1}, \mathrm{~W}_{2} \neq 0, \lambda \neq 0$, or $\rho \neq 0$ Eq. 2 is called Spatial Autoregressive Moving Average (SARMA). Then, if $\rho$ $=0$ and $\lambda=0$ Equation 2 is called linear regression $\mathrm{y}=$ $\mathrm{X} \beta+\varepsilon$, which don't spatial effect.

Spatial Durbin Model (SDM) is special cases of SAR, which adding spatial lag on independent variable (Anselin, 1988). This model was developed because the dependencies in the spatial relationships not only occur in the dependent variable, but also in the independent variable. SDM model is show in Eq. 4:

$y=\rho W_{1} y+\beta_{o}+X \beta_{1}+W_{1} X \beta_{2}+\varepsilon$

Vector coefficient parameter of spatial lag on independent variable is $2 \beta$.

Model Eq. 4 can be formed into Eq. 5 and 6:

$\mathrm{y}=\left(\mathrm{I}-\rho \mathrm{W}_{1}\right)^{-1} \mathrm{Z} \beta+\varepsilon$

$\mathrm{y} \sim \mathrm{N}\left(\left(\mathrm{I}-\rho \mathrm{W}_{1}\right)^{-1} \mathrm{Z} \beta, \sigma^{2} \mathrm{I}\right)$

Where:

$\mathrm{Z}=[\mathrm{I} X \mathrm{WX}] \beta=\left[\beta_{0}, \beta_{1}, \beta_{2}\right]^{\mathrm{T}}$

Parameter estimation of SDM can be performing by Maximum Likelihood Estimation (MLE). It was reference from Ord (1975); Anselin (1988); Arbia (2006); Mur and Angulo (2006) and also LeSage and Pace (2009).

\section{RESULTS}

In 2007, the population of Tuban Regency was $1,127,416$ persons with the population density of 613 persons per $\mathrm{km} 2$. Health Department noted that there are $2.82 \%$ or 31.770 persons who suffering diarrhea. Compared to regencies in East Java, Tuban Regency was ranked the ninth to the incidence of diarrhea. That number has declined over the previous year. It shows from $2.84 \%$ or 31917 persons who suffer diarrhea.

Figure 1 shows the percentage diarrhea by sub district in Tuban. It is known that sub district in suburb area have high percentage of diarrhea than others. There were Parengan (4.12\%), Soko (4.07\%), Rengel (3.79\%), Plumpang (3.39\%), Cross (3.70\%) and Bancar $(3.54 \%)$. Furthermore, districts which have low percentages of diarrhea were located in the central area. There were Montong (0.93\%), Grabagan (1.15\%) and Merakurak $(1.60 \%)$. The pattern distribution of those diarrhea shows that there were clustered sub district that have same diarrhea characteristics. Such us, the high incidence of diarrhea was located in suburb area. 


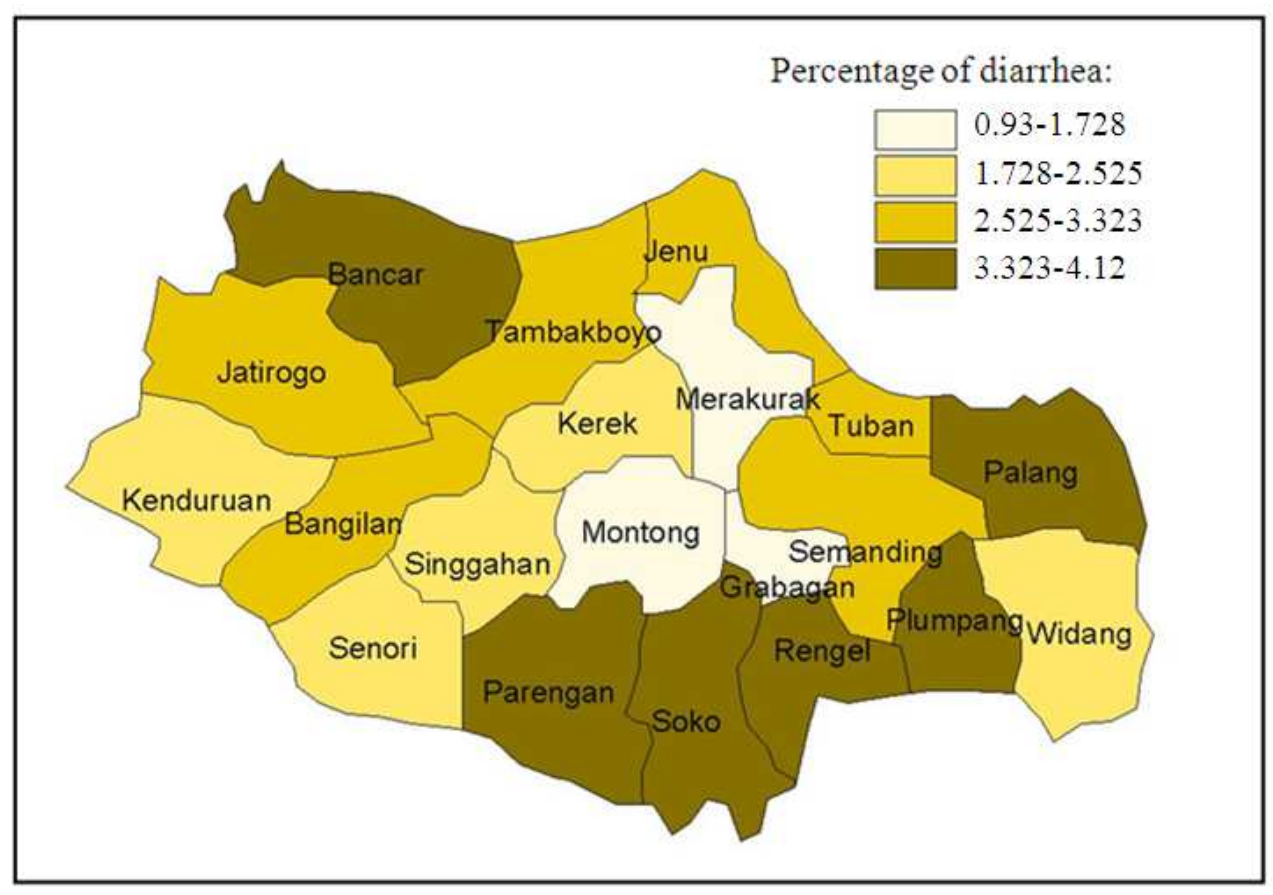

Fig. 1: Percentage of Diarrhea in Tuban Regency 2007 Source: Health Center, 2007

Table 2: Moran's I test

\begin{tabular}{llc}
\hline Variables & Moran's I & $\mathrm{Z}_{\text {score }}$ \\
\hline Diarrhea $(\mathrm{Y})$ & 0,015 & 0,514 \\
Source of drinking water $\left(\mathrm{X}_{1}\right)$ & 0,052 & $1,705^{* *}$ \\
The distance of pumps/wells/springs & 0,178 & $1,896^{* *}$ \\
to shelter dirt/feces( $\left.\mathrm{X}_{2}\right)$ & & \\
Water facilities $\left(\mathrm{X}_{3}\right)$ & 0,005 & 0,446 \\
Defecate facilities $\left(\mathrm{X}_{4}\right)$ & 0,165 & $1,650^{* *}$ \\
Type of toilet $\left(\mathrm{X}_{5}\right)$ & 0,171 & $1,654^{* *}$ \\
Landfills feces $\left(\mathrm{X}_{6}\right)$ & 0,405 & $3,446^{*}$ \\
Health Center $\left(\mathrm{X}_{7}\right)$ & $-0,131$ & $-0,557$ \\
Medical Personnel $\left(\mathrm{X}_{8}\right)$ & 0,053 & 0,836 \\
\hline Note: $(*)$ significant at $\alpha=5 \%,(* *)$ significant at $\alpha=10 \% \mathrm{Z}_{0,025}=$ \\
$1,96, \mathrm{Z}_{0,05}=1,64$
\end{tabular}

The distributions of other variables are presented in Fig. 2. The figure also shows that there were clustered sub district that have same characteristics. Sub districts which have high percentage of households who have type of toilet cubluk or cemplung or don't have toilet were in north area (Fig. 2d). There were Jatirogo, Bancar and Jenu which have 68.492-90.63\%. Then, sub districts in middle area have lower percentage than other.

Moran's I: The result of spatial autocorrelation test was shown in Table 2. The result of spatial autocorrelation test was landfills feces variables $\left(\mathrm{X}_{6}\right)$ have autocorrelation among sub districts at level significant $5 \%$. The results at level significant $10 \%$ were source of drinking variable $\left(\mathrm{X}_{1}\right)$, the distance of pumps/wells/springs to shelter dirt/feces variable $\left(\mathrm{X}_{2}\right)$, defecate facilities $\left(\mathrm{X}_{4}\right)$ and type of toilet $\left(\mathrm{X}_{5}\right)$ have autocorrelation among sub districts. It showed from the value $\mathrm{Z}$ score which exceed $\mathrm{Z}_{0,025}=1,96$ and $\mathrm{Z}_{0,05}=$ 1,64 .

Most of the independent variable have the value of Moran's I greater than Io $=-0.053$. It indicates that there was positive autocorrelation or clustered data pattern. Sub districts which in the some cluster have similar characteristics. The diarrhea incidence as the dependent variable has Moran's I of 0.015 which was not significant both at $\alpha=5 \%$ and $10 \%$. Based on comparison by Io, it indicates that the data pattern is spread. Among sub districts have different characteristics of diarrhea. Other variables that have a pattern of spread were water facilities $\left(\mathrm{X}_{3}\right)$, health center $\left(\mathrm{X}_{7}\right)$, medical personnel $\left(\mathrm{X}_{8}\right)$.

Parameter estimation: The modeling steps in this research were start using the Ordinary Least Square (OLS) method. Modeling by OLS is presented in Table 3. Type of toilet was significant effect to diarrhea at $\alpha=10 \%$. Water facilities significant effect at $\alpha=20 \%$. The coefficients determinansi $\left(\mathrm{R}_{\text {square }}\right)$ is relatively small and the Sum Square Error (SSE) is large. $\mathrm{R}_{\text {square }} 47.2 \%$ shows the magnitude of the variance of the diarrhea incidence which can be explained by the model or 
independent variable in model. Furthermore, testing on residual assumption, residual were normally distributed

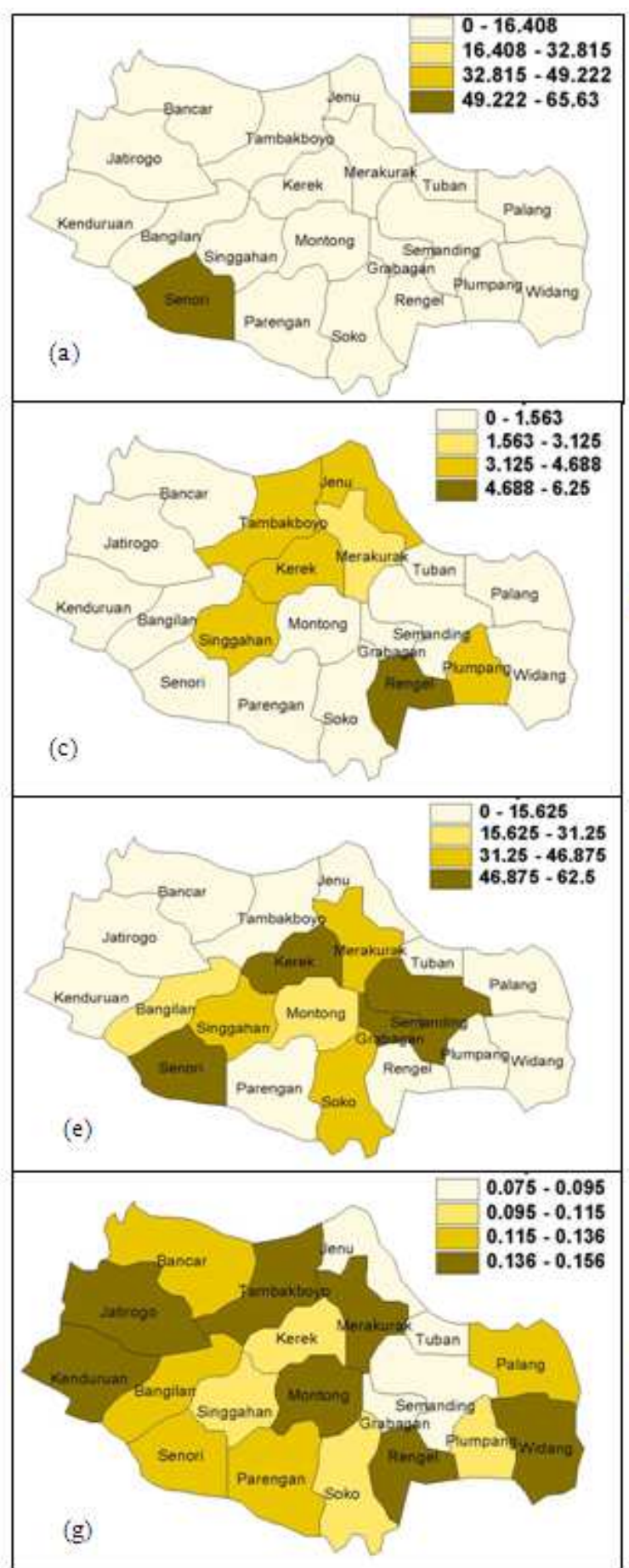

and independent, but not identic or heterodeskedasitas. Parameter estimation on SDM is presented on Table 4.
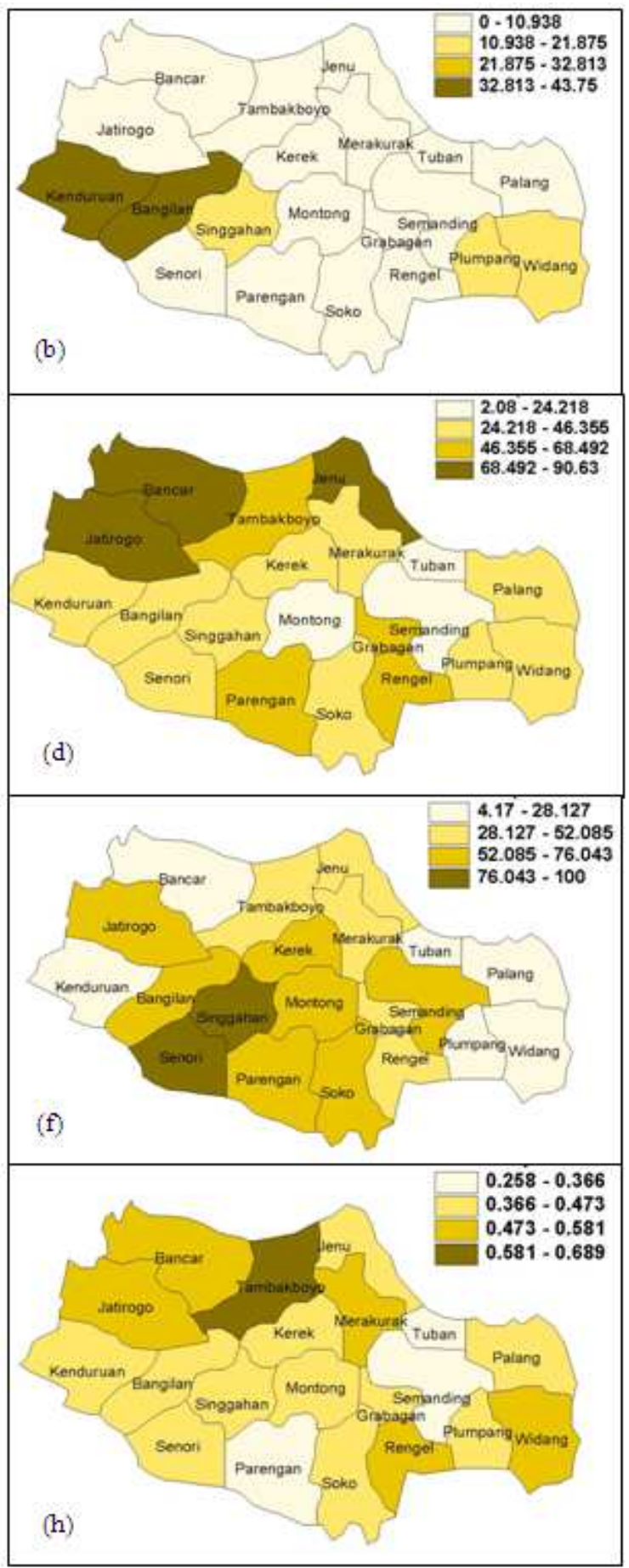

Fig. 2: Persentage of Source of Drinking Water (a), The Distance of Pumps/Wells/Springs to Shelter Dirt/Feces (b), Water Facilities (c), Defecate Facilities (d), Type of Toilet (e), Landfills Feces (f), Health Center (x 1000) (g), Medical Personnel (x 1000) (h) Source: Susenas, 2007 
Table 3: Parameters estimation by OLS

\begin{tabular}{lcc}
\hline Parameters & Estimation & $\mathrm{t}$ \\
\hline$\beta_{0}$ & $-0,000$ & $-0,00$ \\
$\beta_{1}$ & $-0,021$ & $-0,08$ \\
$\beta_{2}$ & $-0,270$ & $-0,94$ \\
$\beta_{3}$ & 0,359 & $1,40 * * *$ \\
$\beta_{4}$ & 0,077 & 0,24 \\
$\beta_{5}$ & $-0,950$ & $-2,03 * *$ \\
$\beta_{6}$ & 0,330 & 0,92 \\
$\beta_{7}$ & $-0,286$ & $-0,88$ \\
$\beta_{8}$ & $-0,217$ & $-0,63$ \\
$\mathrm{R}_{\text {square }}(\%)$ & 47,2 & \\
SSE & 10,030 & \\
\hline Note: $(*)$ significant at $\alpha=10 \%,(* *)$ significant at $\alpha=20 \%, \mathrm{n}=20$ \\
$\tau_{0,95 ; 11} 1,796, \tau_{0,9 ; 11}=1,363$
\end{tabular}

Table 4: Parameter estimation by SDM

\begin{tabular}{lll}
\hline Parameters & Estimation & Wald \\
\hline$\beta_{0}$ & 0.3296 & $3.1280^{* *}$ \\
$\beta_{11}$ & 0.6468 & $3.3371^{* *}$ \\
$\beta_{12}$ & -0.4006 & $3.3434^{* *}$ \\
$\beta_{13}$ & 0.7229 & $15.2629^{*}$ \\
$\beta_{14}$ & 0.1010 & 0.1294 \\
$\beta_{15}$ & -0.4729 & 1.5849 \\
$\beta_{16}$ & -0.3522 & 0.7819 \\
$\beta_{17}$ & 0.6351 & $3.1593^{* *}$ \\
$\beta_{18}$ & -0.7977 & $7.9760^{*}$ \\
\hline$\beta_{21}$ & 2.3123 & $4.8657^{*}$ \\
$\beta_{22}$ & -1.1092 & $3.5350^{* *}$ \\
$\beta_{23}$ & 0.9243 & 0.5276 \\
$\beta_{24}$ & 0.1932 & 0.1202 \\
$\beta_{25}$ & -0.5305 & 0.1142 \\
$\beta_{26}$ & -1.6347 & $2.6102^{* * *}$ \\
$\beta_{27}$ & 2.1869 & $3.8805^{*}$ \\
$\beta_{28}$ & -2.3712 & $7.9906^{*}$ \\
$\rho$ & -0.4293 & $1.8221^{* * *}$ \\
\hline$R_{\text {square }}(\%)$ & & 66,06 \\
SSE & & 5.9743 \\
\hline
\end{tabular}

Note: $(*)$ significant at $\alpha=5 \%,(* *)$ significant at $\alpha=10 \%,(* * *)$ significant at $\alpha=20 \%, \mathrm{n}=20 \chi^{2} 0,05 ; 1=3841, \chi^{2} 0,10 ; 1=2,706$, $\chi^{2} 0,20 ; 1=1,642$

\section{DISCUSSION}

The pattern of diarrhea distribution was clustered and similar characteristics among nearby locations showed that the spatial analysis needs to $\rho$ be done. Furthermore, moran's I show that there were a spatial autocorrelation in some variable.

OLS method has poor performance, because the assumption of identical residual not met. Not identic would effect on residual variances which was not homogeneous. It indications that residual was clustered. Therefore it was necessary for spatial modeling.

The result of SDM was that there was dependency lag on dependen and independent variable. It was shown by parameter $\rho$ and $\beta_{2}$ which significant effect. The significance of the lagged independent variable was indicated by the independent variables with weighting which significant effect to model. These variables were source of drinking water, health center and medical personnel which were significant at $\alpha=$ $5 \%$. Other variables which were significant at $\alpha=20 \%$ were the distance of pumps/wells/springs to shelter dirt/feces and landfills feces. Coefficient determinansi is $66.06 \%$ and sum square error is 5.9743 .

Coefficient of weighted sources of drinking water variable was 2.3123 . It is positive value. It indicates sub district, which was nearby with other sub districts by the high percentage of households who used drinking water from rain water, rivers, unprotected springs and unprotected wells, will has high percentage of diarrheal disease. Otherwise, sub district, which was nearby with other sub districts by the low percentage households who uses drinking water from rain water, rivers, unprotected springs and unprotected wells, will has low diarrheal disease.

Model comparison of OLS and SDM showed that SDM was given better performance than OLS. It has sum square error smaller and there were many parameters which significant effect on model. Based on the analysis, it can be concluded that the lagged dependent and independent variable is very important about the role of modeling the diarrhea and the factors that influence it. Furthermore, based on the relationship between the incidence of diarrhea and ownership of sanitation, water and health facilities, the similarities or differences in the characteristics many sub districts may result an increase or decrease the diarrhea incidence. Example, sub district which have high percentage of households uses a source of drinking water from springs and wells unprotected will be triggered by a nearby districts which have low percentage incidence of diarrhea. These triggers can be done by the relevant programs which have been implemented by government.

\section{CONCLUSION}

Diarrhea case in Tuban Regency has spatial effect. It can be shown from Morans'I and SDM of diarrhea incidence and factors that influence it. The results of SDM show that the lag in the dependent and independent variables significantly affected. These independent variables were source of drinking water, health center and medical personnel which were significant at $\alpha=5 \%$. Furthermore, SDM was give better performance than OLS. It has sum square error smaller and there were many parameters which significant effect on model. In SDM model, lag on dependent and some independent variable.

\section{ACKNOWLEDGEMENT}

Many thanks' for PDPM-LPPM ITS which support the data. 


\section{REFERENCES}

Anselin, L., 1988. Spatial Econometrics: Methods and Models. Ist Edn., Kluwer Academic Publishers, Netherlands, ISBN-10: 9024737354, pp: 304.

Arbia, G., 2006. Spatial Econometrics: Statistical Foundations and Applications to Regional Convergence. 1st Edn., Springer, Berlin Heidelberg New York, ISBN-10: 354032304X, pp: 208.

Arumsari, N. and Sutikno, 2010. Modeling of Diarrhea by Spatial Regression. Case Study: Tuban Regency, East Java Provincy. Proceedings of Seminar Nasional Pasca Sarjana X, Aug. 4-4, ITS Surabaya, pp: 6-31.

Bekti, R.D. and Sutikno, 2011. Spatial Modeling on the Relationship between asset society and poverty in East Java. J. Matematika Sains, 16: 140-146.

Brasington, D.M. and D. Hite, 2005. Demand for environmental quality: A spatial hedonic analysis. Regional Sci. Urban Econ., 35: 57-82. DOI: 10.1016/j.regsciurbeco.2003.09.001

Elobaid, R.M., M. Shitan, N.A. Ibrahim, A.N.A. Ghani and Daud, 2009. Evolution of spatial correlation of mean diameter: A case study of trees in natural Dipterocarp Forest. J. Math. Stat., 5: 267-269. DOI: $10.3844 / j m s s p .2009 .267 .269$

Kazembe, L.N., A.S. Muula and C. Simoonga, 2009. Joint spatial modelling of common morbidities of childhood fever and Diarrhoea in Malawi. Health Place, 15: 165-172. DOI: 10.1016/j.healthplace.2008.03.009

Kissling, W.D. and G. Carl, 2007. Spatial autocorrelation and the selection of simultaneous autoregressive models. Global Ecol. Biogeography, 17: 59-71. DOI: $10.1111 / \mathrm{j} .1466-8238.2007 .00334 . x$
Lee, J. and D.W.S. Wong, 2001. Statistical Analysis with ArcView GIS. Ist Edn., John Wiley and Sons, New York, ISBN-10: 047143776X, pp: 208.

LeSage, J.P. and R.K. Pace, 2009. Introduction to Spatial Econometrics. 1st Edn., Taylor and Francis, Boca Raton, ISBN-10: 142006424X, pp: 340.

LeSage, J.P., 1999. The theory and practice of spatial econometrics. University of Toledo.

Mur, J. and A. Angulo, 2006. The spatial Durbin model and the common factor tests. Spatial Econ. Anal., 1: 207-226. DOI: 10.1080/17421770601009841

Murad, A.A., 2011. Creating a geographical information systems-based spatial profile for exploring health services supply and demand. Am. J. Applied Sci., 8: 644-651. DOI: 10.3844/ajassp.2011.644.651

Myaux, J., M. Ali, A. Felsenstein, J. Chakraborty and A.D. Francisco, 1997. Spatial distribution of watery diarrhoea in children: Identification of "Risk Areas" in a rural community in Bangladesh. Health Place, 3: 181-186. DOI: 10.1016/S13538292(97)00013-0

Ord, K., 1975. Estimation methods for models of spatial interaction. J. Am. Stat. Assoc., 70: 120-126. DOI: 10.1080/01621459.1975.10480272

Wall, M.M., 2004. A close look at the spatial structure implied by the CAR and SAR models. J. Stat. Plann. Inference, 121: 311-324. DOI: 10.1016/S0378-3758(03)00111-3 